\title{
Lipid management in 13,000 high risk cardiovascular patients treated under daily practice conditions: LIMA Registry
}

This article was published in the following Dove Press journal:

Vascular Health and Risk Management

20 February 2013

Number of times this article has been viewed

\section{Juergen R Schaefer' \\ Anselm K Gitt ${ }^{2}$ \\ Frank Sonntag ${ }^{3}$ \\ Achim Weizel ${ }^{4}$ \\ Christina Jannowitz ${ }^{5}$ \\ Barbara Karmann ${ }^{5}$ \\ David Pittrow ${ }^{6}$ \\ Kurt Bestehorn ${ }^{6}$}

'UKGM Klinikum Marburg, PhilippsUniversität Marburg, Marburg/ Lahn, Germany; ${ }^{2}$ Stiftung Institut für Herzinfarktforschung an der Universität Heidelberg, Ludwigshafen, Germany; ${ }^{3}$ Private Practice, HenstedtUlzburg, Germany; ${ }^{4}$ Vorsitzender der DGFF (Lipid-Liga) e.V. Planegg, Germany; ${ }^{5}$ MSD SHARP and DOHME $\mathrm{GmbH}$, Haar, 'Institut für Klinische Pharmakologie, Dresden, Germany
Correspondence: Kurt Bestehorn Institute for Clinical Pharmacology, Medical Faculty, Technical University Dresden, Fiedlerstr. 27, D-0I307 Dresden, Germany

Email kurt.bestehorn@mailbox. tu-dresden.de
Aims: We aimed to document the drug management of patients at high cardiovascular risk in daily practice, with the special focus on lipid-lowering treatment.

Methods and results: In this prospective noninterventional study in 2387 outpatient centers throughout Germany, a total of 13,942 high-risk patients (mean age 65.7 years, 61.6\% males) were treated with simvastatin $40 \mathrm{mg} /$ day at entry as monotherapy. All patients were followed up for 12 months in terms of drug utilization, laboratory values, target attainment, and clinical events (including death, hospitalization, vascular events, and dialysis). Patients had coronary heart disease in $35.0 \%$, diabetes mellitus in $24.4 \%$, and the combination of coronary heart disease plus diabetes mellitus in $25.7 \%$. In $21 \%$ of patients, a cholesterol absorption inhibitor was added to statin therapy at the entry visit, and in $23 \%$, this was added at the follow up visit 6 months later. The target values for low-density lipoprotein-cholesterol $(<2.6 \mathrm{mmol} / \mathrm{L})$ were reached by $31.8 \%$ of patients at entry and by $50.0 \%$ at the end of this registry after 12 months. Mean blood pressure decreased (from 135.9/80.5 $\mathrm{mmHg}$ at baseline) by $3.1 / 1.9 \mathrm{mmHg}$ after 12 months. In patients with documented diabetes, the targeted glycated hemoglobin $\left(\mathrm{HbA}_{1 \mathrm{c}}<6.5 \%\right)$ was reached by $33.5 \%$ at baseline and by $40.0 \%$ after 12 months. Clinical events occurred in $11.7 \%$ of patients between baseline and month 6 , and in $12.0 \%$ between months 6 and 12 .

Conclusion: In patients at high risk for cardiovascular events, comprehensive management under daily practice conditions leads to improvement of lipid, glucose, and blood pressure parameters. There is a need to improve secondary prevention among high-risk patients.

Keywords: dyslipidemia, observation, treatment, risk factors, coronary heart disease, cardiovascular disease

\section{Introduction}

In current mortality statistics, cardiovascular (CV) diseases are still among the leading causes of death. ${ }^{1,2}$ Primary and secondary prevention of myocardial infarction and stroke have a central role in the management of patients at increased CV risk. ${ }^{3-5} \mathrm{Current}$ guidelines highlight the importance of lowering elevated lipid levels, in particular low-density lipoprotein cholesterol (LDL-C). Patients at high CV risk, eg, those with manifest coronary heart disease (CHD) or diabetes mellitus (DM), should meet the LDL-C target value of $<2.6 \mathrm{mmol} / \mathrm{L}(<100 \mathrm{mg} / \mathrm{dL})$, and those at very high $\mathrm{CV}$ risk should aim at even lower levels. ${ }^{5}$

According to current prescription statistics, the great majority of patients with high lipid levels receive statins and a smaller proportion receive other drugs, such as cholesterol absorption inhibitors (CAI), fibrates, nicotinic acid, or others. ${ }^{6}$ However, current data on the day-to-day management of patients at high CV risk indicate that their 
use is not consistent, and part of this inconsistency may be due to clinical inertia, physician misconception about drug efficacy, or other factors. ${ }^{7,8}$

The current study (Leitliniengerechte Lipidtherapie und Zielwerterreichung bei Risikopatienten im klinischen Alltag, LIMA) aimed to examine the utilization of the most commonly used statin in Germany, simvastatin, in the daily treatment of high-CV risk patients, in terms of patient characteristics, risk factor management, lipid target attainment, and outcomes, during a 12-month follow-up period. We focused on lipid-lowering drug treatment, and analyzed patients in the total cohort and in three subgroups, namely with CHD alone, DM alone, or the combination of both conditions.

\section{Methods}

\section{Design and conduct}

This was a prospective, noninterventional study in 2387 centers all over Germany, performed between September 2007 and March 2009. The design and basic results of the study have been reported in the German language recently., ${ }^{9,10}$

Office-based family physicians, general practitioners, and cardiologists/diabetologists in family care treated patients within the framework of either statutory health insurance program or private insurance. The observational plan and the case report form of the study were approved by the Ethics Committee of the Bavarian Federal Medical Council. The study was conducted in accordance with the applicable laws and regulations in Germany. It followed Good Epidemiological Practice (GEP) guidelines. ${ }^{11}$ All patients gave written, informed consent. The study was registered in the database of the German Association of Research-based Pharmaceutical Companies (http://www.VfA.de). The study protocol did not stipulate any specific treatment or interventions, and physicians were requested not to change their typical practice in treating patients.

\section{Patients}

Adult patients were eligible for documentation, if they were at high risk for $\mathrm{CV}$ events and had received $40 \mathrm{mg}$ simvastatin as monotherapy once daily without interruption for at least four weeks at the time of recruitment. "High risk" for CV events was defined as an established coronary heart disease (CHD), and/or diabetes mellitus (DM), and/or peripheral arterial disease (PAD). Application of other lipid-lowering therapy was an exclusion criterion. To avoid selection bias, consecutive enrollment of six eligible patients per center was scheduled. Three visits were planned: at baseline, after approximately 6 months, and 12 months.
Documented parameters comprised patient demographics (age, gender, height, and body weight), insurance status, disease-management program (DMP) participation, $\mathrm{CV}$ risk factors, concomitant diseases, and concomitant drugs before and at inclusion in the study (with particular focus on lipid-modifying medications). All diagnoses were provided by the treating physicians. CHD included myocardial infarction, angina pectoris, coronary artery bypass graft $(\mathrm{CABG})$, or percutaneous coronary intervention (PCI).

The latest available standard laboratory parameters (total cholesterol [TC], low-density lipoprotein cholesterol [LDL-C], high-density lipoprotein cholesterol [HDL-C], and triglycerides [TG]) were recorded on standardized case report forms (CRFs) for the objective assessment of lipid goal attainment. Further, physicians were requested to state whether in their opinion, the current treatment led to individual target level attainment (for a subjective assessment of lipid goal attainment). Physicians received feedback from the study management about the target level attainment of their patients after the entry visit and the final visit (Figure 1). Blood pressure, glycated hemoglobin $\left(\mathrm{HbA}_{1 \mathrm{c}}\right)$ (in diabetic patients), and fasting blood glucose values were documented, if available.

At the two follow-up visits, current medication (with focus on lipid modifying therapy) was recorded, as were current lipid, blood pressure, and glucose values. In addition, the following clinical events were explicitly asked for: hospitalization, death, myocardial infarction, stroke, transient ischemic attacks, coronary angiography, PCI, CABG, newly diagnosed PAD, first-time dialysis, and diabetes-related amputations. The exact date of events was not recorded. Physicians had the choice between internet-based data entry (web-based CRFs) or paper-based data collection. Onsite quality and plausibility checks were performed by onsite monitoring, with source data verification in 50 randomly selected centers.

\section{Statistical analysis}

Based on a prespecified statistical plan, analyses on efficacy parameters were performed descriptively, and comparisons were not tested for significance. Continuous numeric variables were expressed as number of evaluable values, mean, standard deviation, median, minimum, and maximum. For categorical variables, frequency counts were applied (absolute and relative frequencies).

Of the 13,942 patients eligible for analysis, 11,998 (87.4\%) completed the baseline visit and the visit at 6 months and 10,532 (76.8\%) completed all three visits. Patients were 


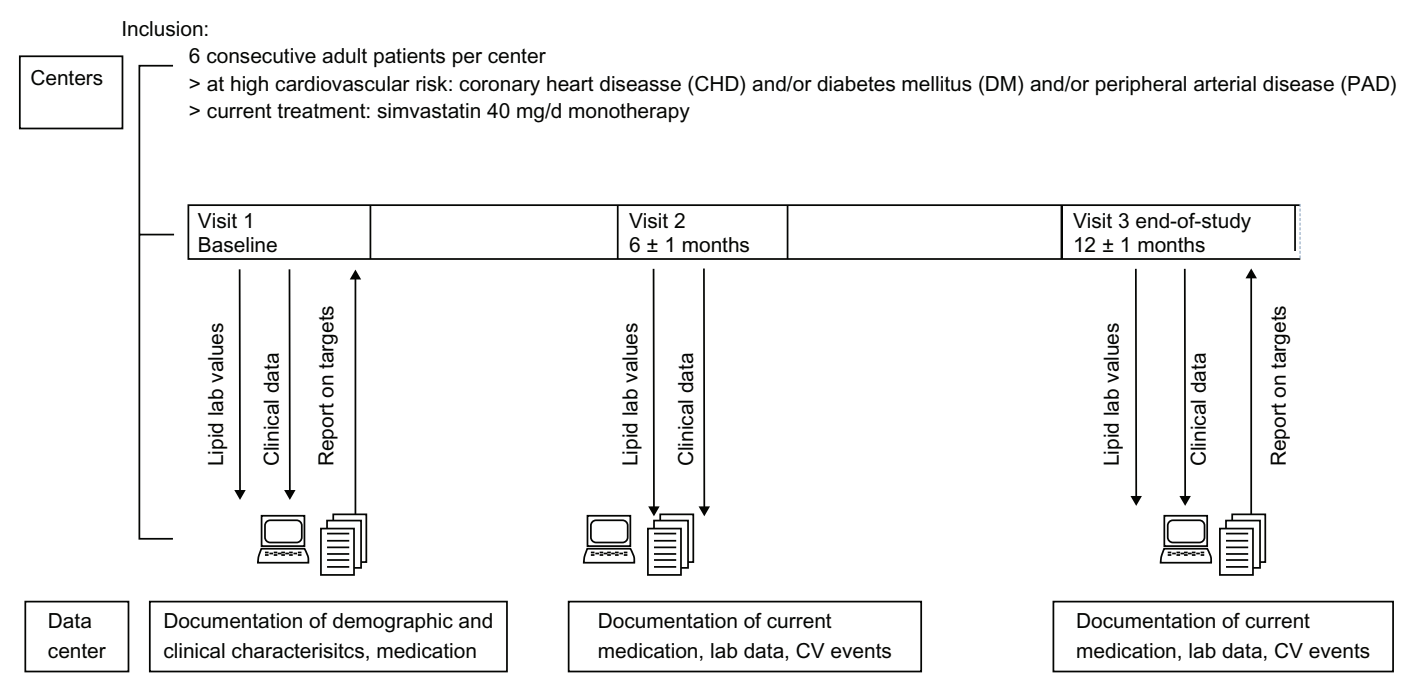

Figure I Study protocol. The figure displays the study flow and interaction between centers and the data center.

Abbreviation: $\mathrm{CV}$, cardiovascular.

categorized according to the presence of three subgroups (CHD alone, DM alone, CHD + DM). Due to likely underreporting of subclinical $\mathrm{PAD},{ }^{12}$ no subgroup analysis was performed on these patients, but they were included in the total cohort.

Implausible laboratory values were removed from the database (and set as "missing"). Data processing and analysis was performed with SAS Software, release 9.2 (SAS Institute Inc, Cary, NC, USA).

\section{Results \\ Baseline \\ Patient characteristics}

In the total cohort of 13,942 patients, the mean age was 65.7 years (range: 19-98). Males were more frequent than females $(61.6 \%$ vs $38.4 \%)$. The great majority of patients were covered by statutory health insurance (95.2\%); by this, the proportion of patients with private health insurance (which in Germany, is at about 11\%) was slightly underrepresented.

Patients with CHD + DM were older and had higher rates of comorbidities and risk factors compared with patients in the CHD and DM groups (Table 1). In the presence of CHD, the ratio of males to females was about $2: 1$.

\section{Concomitant diseases and risk factors}

$\mathrm{CV}$ diseases that qualified patients as "high risk" are shown in Figure 2. CHD was the leading disease $(70.6 \%$ of patients), followed by DM (58.2\%), and by PAD (14.9\%). A substantial proportion of patients had combinations of these $\mathrm{CV}$ diseases. Other cardiovascular comorbidities and risk factors were also frequent, with arterial hypertension being the leading condition $(87.0 \%)$. Overall, the majority of patients $(86.1 \%)$ were affected by two or more risk factors or concomitant conditions, whereas only $12.5 \%$ had one risk factor or concomitant condition and $1.4 \%$ had none.

The number of risk factors was higher in the CHD and CHD + DM groups than in the DM group.

\section{Medications}

Medications for cardiovascular or metabolic diseases were frequent, as expected in this population (Figure 3 ). They most commonly comprised beta blockers (66.3\%), acetyl salicylic acid (65.3\%), and angiotensin-converting-enzyme (ACE) inhibitors $(59.8 \%)$. In the subgroup of diabetic patients, metformin was administered in $54.2 \%$ and insulin

Table I Characteristics of patients at baseline (total cohort and subgroups)

\begin{tabular}{lllll}
\hline Parameter & Total* & \multicolumn{3}{l}{ Subgroups } \\
\cline { 3 - 5 } & & DM & CHD & CHD + DM \\
\hline $\mathrm{n}$ & 13,942 & 3397 & 4884 & 3579 \\
Age, years & $65.7 \pm 10.3$ & $63.4 \pm 10.5$ & $65.2 \pm 10.5$ & $67.6 \pm 9.4$ \\
Gender, male, \% & 61.6 & 49.5 & 66.1 & 63.5 \\
BMl, kg/m ${ }^{2}$ & $29.2 \pm 4.7$ & $30.6 \pm 5.1$ & $27.8 \pm 3.9$ & $30.0 \pm 4.7$ \\
Risk factors, \% & & & & \\
$\quad 0$ & 1.4 & 4.0 & 0.6 & 0.2 \\
$\quad$ I & 12.5 & 28.3 & 9.3 & 5.4 \\
$2+$ & 86.1 & 67.7 & 90.1 & 94.3 \\
\hline
\end{tabular}

Notes: *includes subgroups and other risk patients, eg, patients with peripheral arterial disease.

Abbreviations: DM, diabetes mellitus; CHD, coronary heart disease; BMI, body mass index. 


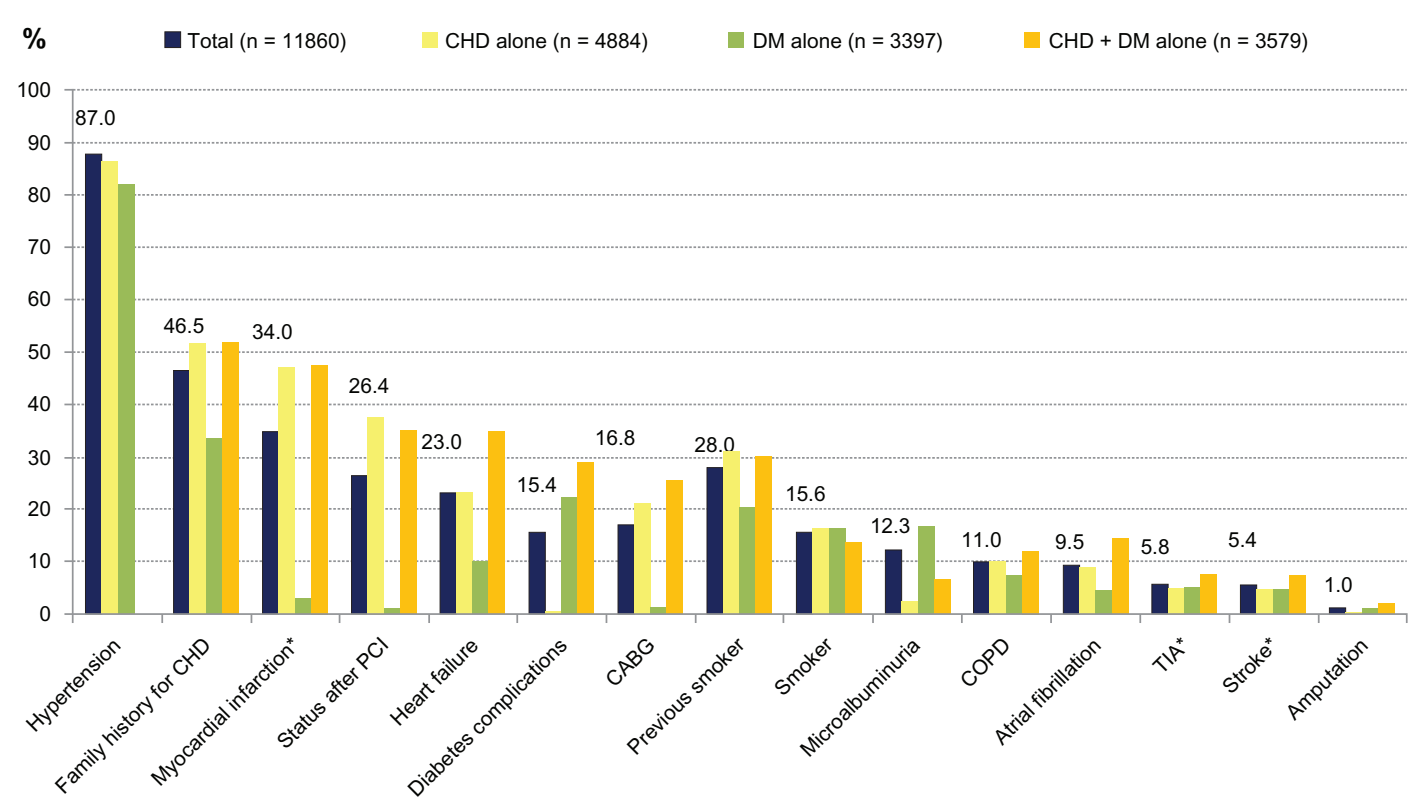

Figure 2 Concomitant diseases and risk factors for cardiovascular disease (total and subgroups). Notes: Percentages above columns refer to the total group. *prior to inclusion.

Abbreviations: CHD, coronary heart disease; DM, diabetes mellitus; PCl, percutaneous coronary intervention; CABG, coronary artery bypass graft; COPD, chronic obstructive pulmonary disease; TIA, transient ischemic attack.

in $29.1 \%$, while sulfonylureas, glitazones, and glinides were used less frequently.

\section{Lipid-modifying medication}

In accordance with the respective inclusion criterion (stable after at least 4 weeks on simvastatin $40 \mathrm{mg}$ ), patients received this agent at entry (with the exception of 210 patients $[1.5 \%])$.

\section{Follow up}

\section{Lipid-modifying medication}

After the baseline visit, the majority of patients (67.6\%) were maintained on simvastatin monotherapy for over 12 months. After baseline, the $80 \mathrm{mg} /$ day dose was used infrequently (3.2\%), and the majority of patients (79.4\%) remained on the $40 \mathrm{mg} /$ day dose. Further, simvastatin $20 \mathrm{mg}$ /day was used by $8.4 \%, 10 \mathrm{mg} /$ day by $0.9 \%$, or an unknown dose by $6.5 \%$. In $20.6 \%$, a CAI was added at the baseline visit; and in $23.3 \%$, this was added at the first follow-up visit. A switch to other statins was rare (1.4\%). Table 2 displays the utilization patterns of lipid-modifying drugs during the course of the study.

\section{Lipid profile and target level attainment}

All lipid values improved during the follow-up period (Figure 4A). In the total cohort, TC decreased (from $5.42 \mathrm{mmol} / \mathrm{L}$ ) by $0.59 \mathrm{mmol} / \mathrm{L}$ after 12 months, LDL-C decreased (from $3.19 \mathrm{mmol} / \mathrm{L}$ ) by $0.49 \mathrm{mmol} / \mathrm{L}$, HDL-C increased (from $1.32 \mathrm{mmol} / \mathrm{L}$ ) by $0.03 \mathrm{mmol} / \mathrm{L}$, and $\mathrm{TG}$ decreased (from $2.15 \mathrm{mmol} / \mathrm{L}$ ) by $0.23 \mathrm{mmol} / \mathrm{L}$.

Figures 4B-D display lipid parameters at the three visits in the CHD, DM, and CHD + DM subgroups. Lipid-lowering effects were similar across the three groups, while at all visits, TG was higher in the DM and CHD + DM groups compared with the CHD group.

In terms of target level attainment, physicians stated subjectively that LDL-C levels of their patients were achieved in $44.5 \%$ of cases at baseline, and in $74.2 \%$ after 12 months (Figure 5A). Based on laboratory values, the goal attainment rates $(<2.59 \mathrm{mmol} / \mathrm{L})$ were lower, namely $31.8 \%$ at baseline and $50.1 \%$ after 12 months. Subjective and objective LDLtarget achievement rates at month 12 were highest in the CHD + DM group, followed by the CHD and DM groups (Figure 5B-D).

\section{Blood pressure and blood glucose}

Mean blood pressure decreased (from 135.9/80.5 mmHg at baseline) by $3.1 / 1.9 \mathrm{mmHg}$. The $<140 / 90 \mathrm{mmHg}$ target was met by $53.0 \%$ of patients at baseline, and by $65.8 \%$ after 12 months. The mean fasting blood glucose was $6.61 \mathrm{mmol} / \mathrm{L}$ at entry and $6.44 \mathrm{mmol} / \mathrm{L}$ after 12 months. Mean $\mathrm{HbA}_{1 \mathrm{c}}$ (measured in patients with diabetes only) was $6.9 \%$ at entry and $6.7 \%$ after 12 months; the $<6.5 \%$ goal was achieved by $33.5 \%$ of patients at baseline and by $40.0 \%$ after 12 months. 


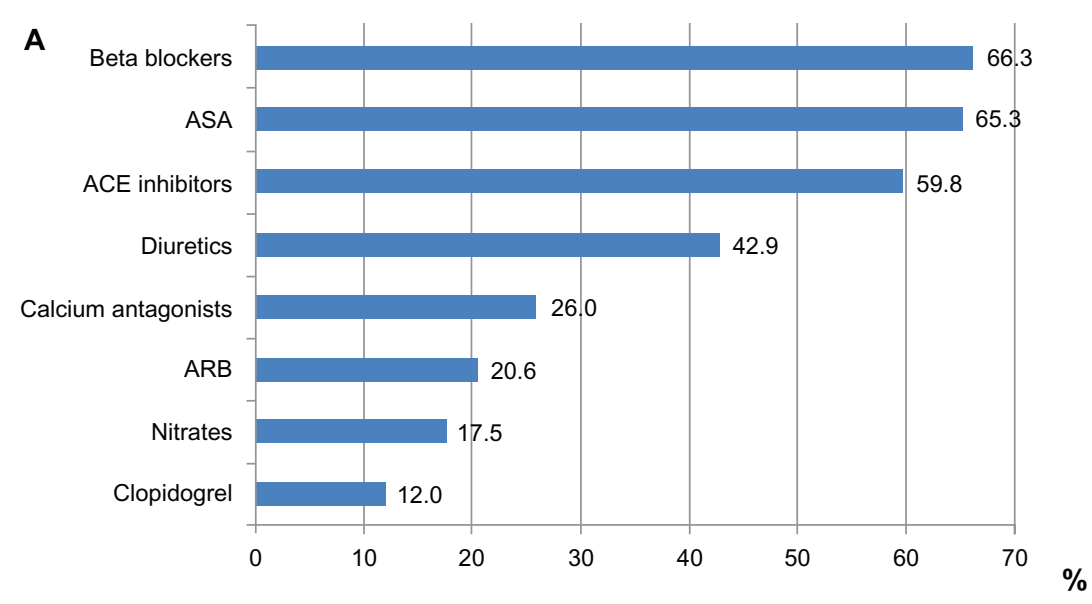

B

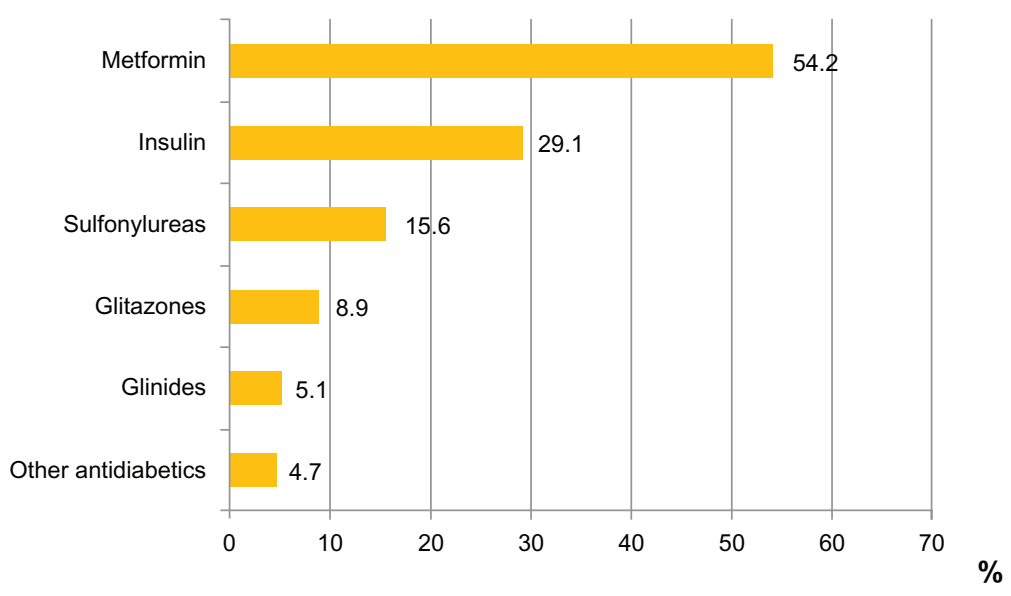

Figure 3 Medications at entry. (A) Concomitant antihypertensive, cardiac and antiplatelet medications at entry; \% refer to the total group; (B) Antidiabetic medication at entry; \% refer to the patients with diabetes mellitus.

Notes: Medications $\geq 5 \%$ in the total cohort are shown.

Abbreviations: ASA, acetyl salicylic acid; ARB, angiotensin receptor blockers.

\section{Clinical events}

Table 3 displays events that occurred in the period between baseline and month 6 , and in the period between month 6 and month 12. In total, 1407 events (11.7\% of patients were affected) were documented between baseline and month 6 , and
1268 events ( $12.0 \%$ of patients) between month 6 and month 12 . Hospitalization was the most frequently reported event (5.5\% of patients at month $6,6.1 \%$ of patients at month 12$)$. Fifty-six patients died during the study $(0.5 \%)$; among these, myocardial infarction caused death in eight patients, stroke in six patients.

Table 2 Patterns of lipid-lowering drug utilization at the three visits

\begin{tabular}{|c|c|c|c|c|}
\hline & At baseline & Baseline to month 6 & Month 6 to month 12 & $\begin{array}{l}\text { Frequency of } \\
\text { described pattern (\%) }\end{array}$ \\
\hline I & Simvastatin $\rightarrow$ & Simvastatin $\rightarrow$ & Simvastatin & 67.6 \\
\hline 2 & Simvastatin $\rightarrow$ & Simvastatin $+\mathrm{CAl} \rightarrow$ & Simvastatin + CAl & 18.5 \\
\hline 3 & Simvastatin $\rightarrow$ & Simvastatin $\rightarrow$ & Simvastatin + CAl & 4.8 \\
\hline 4 & Simvastatin $\rightarrow$ & Simvastatin $+\mathrm{CAl} \rightarrow$ & Simvastatin & 2.1 \\
\hline 5 & Simvastatin $\rightarrow$ & Other statin* $\rightarrow$ & Other statin* & $\mathrm{I} .4$ \\
\hline 6 & Simvastatin $\rightarrow$ & Fibrate $\rightarrow$ & Fibrate & 0.2 \\
\hline 7 & Simvastatin $\rightarrow$ & Nicotinic acid $\rightarrow$ & Nicotinic acid & 0.2 \\
\hline 8 & Simvastatin $\rightarrow$ & \multicolumn{2}{|c|}{ Any other pattern of combination therapy with lipid-lowering medication } & 5.1 \\
\hline
\end{tabular}

Notes: The table shows the distribution of the most frequently used prescribing patterns during the course of the study. *'other statins" can be any of the following: pravastatin, atorvastatin, fluvastatin, or lovastatin. Abbreviation: CAI, cholesterol absorption inhibitor. 
A

$\square$ Baseline $\square$ Month $6 \quad$ Month 12

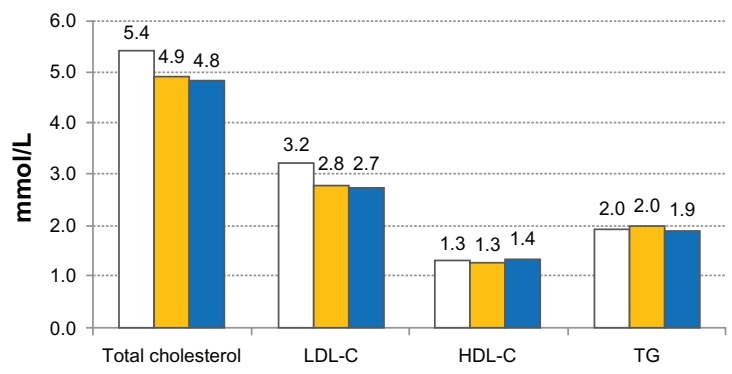

B

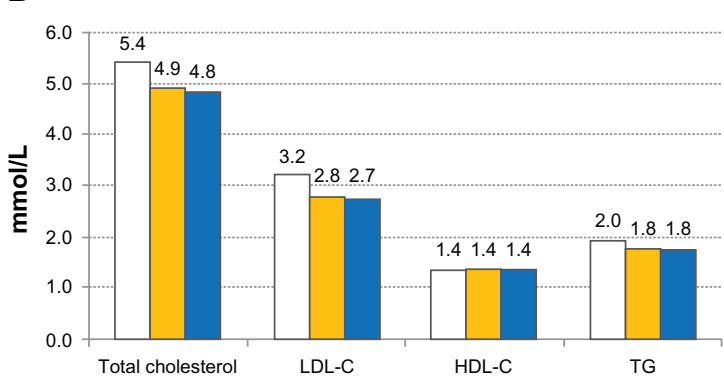

C

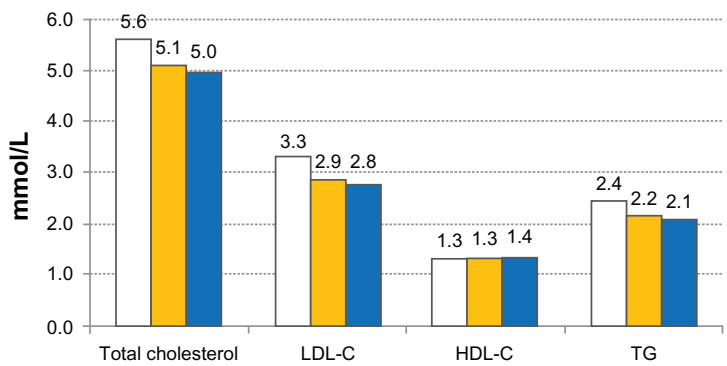

D

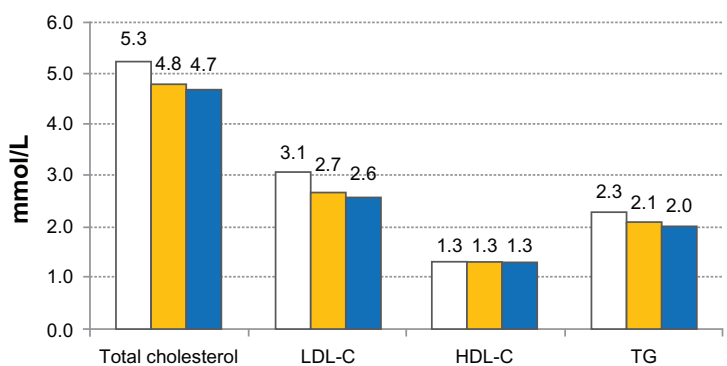

Figure $4 \mathrm{Lipid}$ values (mmol/L) at baseline and follow-up visits, in the total cohort and subgroups of patients with CHD, DM, and CHD + DM. (A) Total cohort; (B) Subgroup CHD $(n=4884) ;$ (C) Subgroup DM ( $n=3397)$; (D) Subgroup CHD + DM $(n=3579)$. Abbreviations: CHD, coronary heart disease; DM, diabetes mellitus; LDL-C, lowdensity lipoprotein cholesterol; HDL-C, high-density lipoprotein cholesterol; TG, triglycerides.

Event rates were highest in the CHD + DM groups in both observation periods, mainly driven by hospitalizations as the most frequent event.

\section{Discussion}

The present large-scale registry provides insights into the management of patients with lipid disorders who are at high
A

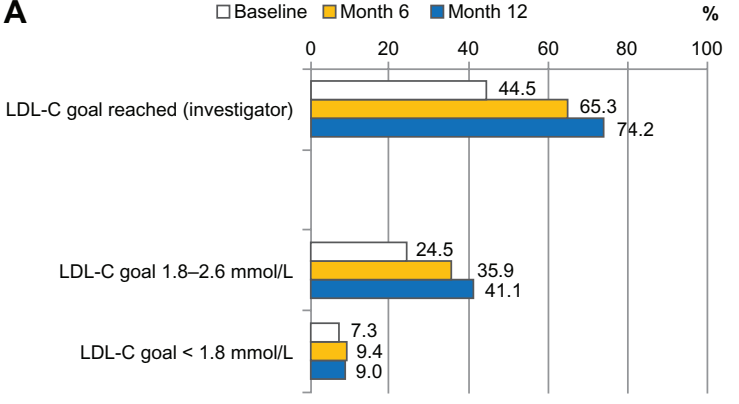

B

$\square$ Baseline $\square$ Month $6 \quad \square$ Month $12 \quad \%$

LDL-C goal reached (investigator)

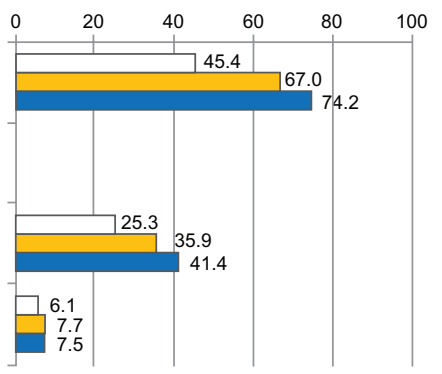

C

LDL-C goal 1.8-2.6 mmol/L

LDL-C goal $<1.8 \mathrm{mmol} / \mathrm{L}$

$\square$ Baseline $\square$ Month $6 \quad$ Month 12

$\%$

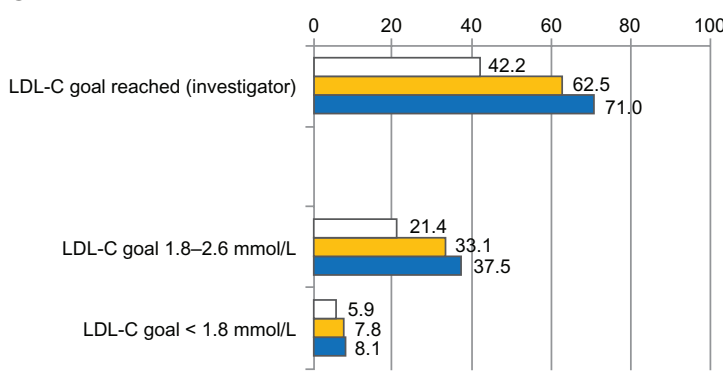

D

$\square$ Baseline $\square$ Month $6 \quad \square$ Month 12
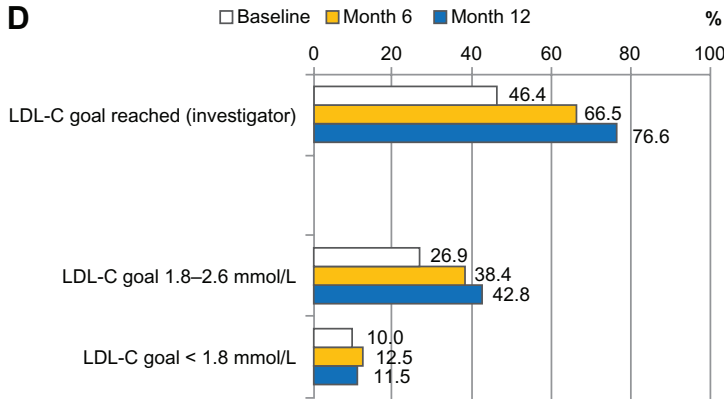

Figure 5 LDL-C goal achievement (\%) as assessed by investigator (subjective) and according to laboratory findings (objective). (A) Total cohort; (B) Subgroup CHD $(n=4884)$; (C) Subgroup DM ( $n=3397)$; (D) Subgroup CHD + DM $(n=3579)$.

Note: To convert from $\mathrm{mmol} / \mathrm{L}$ to $\mathrm{mg} / \mathrm{dL}$, multiply by 38.67 .

Abbreviations: CHD, coronary heart disease; DM, diabetes mellitus; LDL-C, lowdensity lipoprotein cholesterol.

$\mathrm{CV}$ risk due to manifest $\mathrm{CHD}, \mathrm{DM}$ as coronary equivalent, or other vascular diseases.

While at first glance the study criteria seem restrictive, as only patients on $40 \mathrm{mg}$ of simvastatin were eligible, this drug is by far the most frequently administered statin. Due to specific refunding rules, simvastatin is considered the lead statin in Germany. According to an analysis of all prescriptions paid 


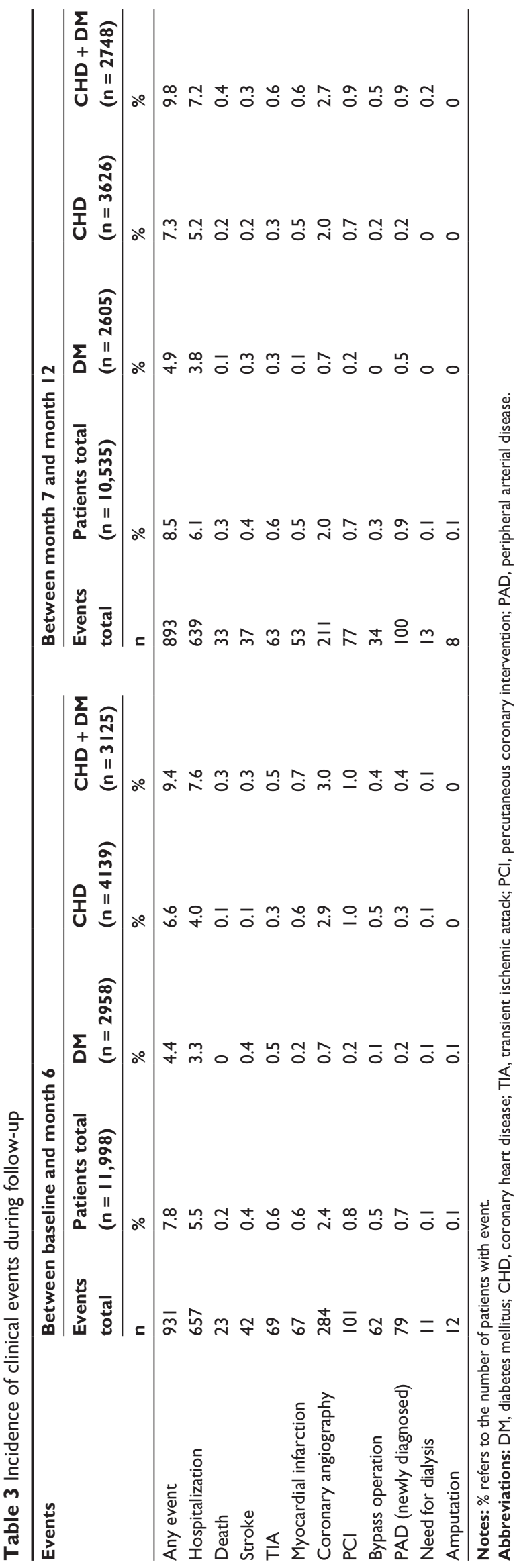

by the statutory health insurance in 2010, of the 1471 million defined daily doses of statins (which allow treatment of 4 million patients, at standard doses), 1277 million were for simvastatin, 91 million were for pravastatin, 62 million for fluvastatin, 18 million for atorvastatin, and 5 million were for lovastatin and rosuvastatin each. The simvastatin $40 \mathrm{mg} /$ day entry dose, used as the inclusion criterion in our study, is somewhat higher than in other studies documenting actual care: in the DYSIS cross-sectional study, ${ }^{13} 84 \%$ of patients treated for lipid disorders received simvastatin, and the mean simvastatin dose (or in case of other statins, the equivalent dose) was $27 \mathrm{mg} /$ day, with no major differences between high-risk patients and other patients.

The LIMA registry only included patients at high risk for CV events. The Third Report of the National Cholesterol Education Program expert panel and Adult Treatment Panel (NCEP ATP III) describes that lipid disorders, in particular dyslipidemia and hypercholesterolemia, are the most important modifiable risk factors for $\mathrm{CV}$ disease. ${ }^{5}$ The central role of dyslipidemia as a CV risk factor has been highlighted by the global case-control INTERHEART study, ${ }^{14}$ in which hypercholesterolemia was responsible for $54 \%$ of the population-attributable risk for myocardial infarction. Rigorous dyslipidemia treatment goals have been set for patients with manifest CHD and/or type $2 \mathrm{DM}^{5}{ }^{5}$ These primarily focus on LDL-C (and total cholesterol), because, according to the meta-analysis by Baigent et a $1{ }^{15}$ of 14 prospective studies, for every $1 \mathrm{mmol} / \mathrm{L}(39 \mathrm{mg} / \mathrm{dL})$ decrease in LDL-C, the risk of major cardiovascular events is reduced by $21 \%$. With respect to the substantial residual cardiovascular risk of statin-treated patients, ${ }^{16}$ elevated triglyceride levels should be lowered as well, and low HDL-C values should be raised. ${ }^{17}$

In our study, lipid target level attainment rates improved over the course of the trial. The objective target level attainment rates (ie, LDL-C $<2.59 \mathrm{mmol} / \mathrm{L} ;<100 \mathrm{mg} / \mathrm{dL}$ ) were of the same order as was seen in other recent studies; for example, in the $2 \mathrm{~L}$ registry performed in 2006 , office-based cardiologists treated a high-risk population similar to ours and achieved target LDL-C levels in 36.2\% (CHD + another coronary equivalent), in $39.7 \%$ (CHD only), and in $27.2 \%$ (coronary equivalent only) of patients. ${ }^{18}$ In both studies, $2 \mathrm{~L}$ and LIMA, physicians claimed substantially higher target attainment rates when asked for their subjective assessment. This provides the impression that physicians, at least in a subset of patients, deviate from the guidelines' recommendations. Several explanations may account for this finding. First, physicians may underestimate the individual risk to their patient. Sager et a $\mathrm{l}^{19}$ used logistic regression to analyze 
whether 907 primary care physicians utilized risk factors and comorbidities appropriately for the assignment of correct LDL-C target values. They found that overall, physicians estimated recommended LDL-C target values correctly in only about half of their 25,000 patients ( $55.1 \%$ of male vs $49.1 \%$ of female patients); poor perception of $\mathrm{CV}$ risk resulted in lower rates of objective LDL-C target achievement. Second, the treat-to-target paradigm and the stipulated LDL-C targets in the NCEP ATP III current guidelines have been challenged by some experts. ${ }^{20}$ Third, enduring discussions about whether $\mathrm{DM}$ is a coronary equivalent or not (challenging the stringent LDL-C targets set by NCEP ATP III) ${ }^{21-23}$ could have contributed to noncompliance with guidelines. However, in a population-based observational study in the entire Danish population of 3.3 million people, Schramm et $\mathrm{al}^{24}$ found that patients requiring glucose-lowering therapy who were at least 30 years of age exhibited a CV risk (composite of myocardial infarction, stroke, and $\mathrm{CV}$ death) comparable to nondiabetics with a prior myocardial infarction, regardless of sex and diabetes type, supporting the concept of diabetes as a CHD equivalent.

Few physicians prescribed statins at high doses, even if lipid goals were not met. This can be explained, among other factors, by the fear of increased rates of side effects. ${ }^{16}$ In the recent SEARCH study, the simvastatin $80 \mathrm{mg} /$ day dose was associated with an increased rate of myopathy $(0.9 \%$ vs $0.03 \%$ in the simvastatin $20 \mathrm{mg} /$ day group). ${ }^{25}$ This finding formed the basis for the US FDA recommendation to avoid starting treatment with the $80 \mathrm{mg} /$ day dose and to continue use of this strength only in patients who have already been taking it for 12 months or longer without negative effect. ${ }^{26}$ Furthermore, the $80 \mathrm{mg} /$ day dose lowers the LDL-C only slightly, by an additional decrease of roughly $6 \%$ over simvastatin $40 \mathrm{mg} /$ day (in agreement with the "rule of six"). ${ }^{27,28}$

In addition, special German reimbursement rules prefer the prescription of simvastatin. All these together might explain why physicians preferred to use combination therapy with a CAI on top of simvastatin, if needed, to achieve treatment target. In $25 \%$ of cases, a CAI was added to simvastatin. According to the meta-analysis by Mikhailidis et $\mathrm{al}^{29}$ of 13 studies including 5080 patients, the add-on of a CAI is significantly more effective than doubling the statin dose (odds ratio 2.5; $P=0.007$ ) for the attainment of LDL-C targets.

With respect to outcomes, at first glance the LIMA registry shows the high incidence of events that patients suffer in this high-risk population, which is predominantly due to the frequent hospitalization events. The rather low death rate $(\mathrm{n}=56 ; 0.5 \%)$ in LIMA is remarkable and substantially below the event rates observed in other registries. In addition, the rates of myocardial infarction and stroke are lower than one might expect from other registries. For example, in the current $3 \mathrm{~A}$ registry focusing on patients with hypertension (often with multiple comorbidities), the death rate after 12 months was $0.8 \%$, and the combined rate of death, myocardial infarction, and stroke was $1.3 \% .{ }^{30}$ Further, in the German cohort of the Reduction of Atherothrombosis for Continued Health Registry (REACH), after 12 months, $2.1 \%$ of the patients with symptomatic atherothrombotic disease (CHD, cerebrovascular disease, and/or PAD) and $1.5 \%$ of patients with at least three $\mathrm{CV}$ risk factors had died of a CV event, and $5.8 \%$ of symptomatic atherothrombotic patients and $2.5 \%$ of patients with risk factors had reached a combined endpoint consisting of $\mathrm{CV}$ death, myocardial infarction, and stroke. ${ }^{31}$ The reasons for the low event rates in LIMA remain unclear. Possibly the reporting of LDL-C achievement rates to the treating physicians resulted in more aggressive lipidlowering treatment in patients with missed targets. However, it is not possible to quantify this effect. While it appears that the lipid-lowering treatment was safe and effective overall, the additional LDL-C-lowering effect due to CAI was modest (about 10\%) and far below the effect achieved in controlled clinical trials. ${ }^{29,32}$ This effect may be attributed to insufficient compliance, among other factors. ${ }^{33}$

In the analysis by subgroup, patients with CHD + DM had more risk factors and individual comorbidities compared with the other two groups. In the presence of CHD, LDL$\mathrm{C}$-control rates were higher compared with the DM group. Various studies have reported that the treatment intensity of physicians increases at a late stage, once complications have occurred..$^{34,35}$

Further methodological issues have to be taken into account when interpreting the results of the present registry. Participating physicians and patients may well differ from those refusing to participate, as they may represent a positive selection of a physician sample, with better outcomes. Further, the study was nonrandomized, did not include a control group, and was not blinded, which may have introduced bias that confounded the indication or overestimation of treatment effects. ${ }^{36}$ Diet and physical activity were not assessed. Clinical events were collected according to commonly accepted registry rules, but were not adjudicated. No safety information was gathered in the context of this study. 


\section{Conclusion}

The present LIMA registry shows that by intensifying lipidlowering treatment, physicians were able to substantially increase the number of patients at LDL-C target and to improve other lipid parameters as well as blood pressure and glucose levels. However, LDL-C control rates are not yet optimal. Treatment effects were consistent across the CHD, DM, and CHD + DM subgroups, but event rates were highest in the latter group. Combination therapy of statin plus CAI offers additional patients the chance to achieve targets.

\section{Author contributions}

Concept/design: JRS, KB, AKG, FS, AW, CJ. Data analysis/ interpretation: JRS, KB, AKG, FS, AW, BK, DP. Drafting of article: DP, KB. Critical revision of article: JRS, AKG, CJ, KB. Approval of article: all. Funding secured by: CJ, $\mathrm{BK}, \mathrm{KB}$.

\section{Acknowledgments}

The registry was supported by MSD SHARP and DOHME GmbH, Haar, Germany.

\section{Disclosure}

JRS serves as a consultant for MSD/ESSEX and received lecture fees by MSD/ESSEX, Roche, Sanofi, Genzyme and B Braun. DP has received consultancy honoraria from MSD, Sanofi, Pfizer and Novartis. KB is a former employee of MSD; CJ and BK are current, full-time employees of MSD. Apart from this, the authors report no conflicts of interest.

\section{References}

1. World Health Organization. The Global Burden of Disease: 2004 Update. Geneva: World Health Organization; 2008. Available from: http://www. who.int/healthinfo/global_burden_disease/2004_report_update/en/index. html. Accessed September 13, 2012.

2. Centers for Disease Control and Prevention (CDC). QuickStats: Ageadjusted death rates for heart disease and cancer - United States, 1999 - 2009*. MMWR [series on the Internet]. Jun 2011;60(21):713. Available from: http://www.cdc.gov/mmwr/preview/mmwrhtml/ mm6021a6.htm?s_cid=mm6021a6_w. Accessed November 28, 2012.

3. Goldstein LB, Adams R, Alberts MJ, et al. Primary prevention of ischemic stroke. A guideline from the American Heart Association/ American Stroke Association Stroke Council:Cosponsored by the Atherosclerotic Peripheral Vascular Disease Interdisciplinary Working Group; Cardiovascular Nursing Council; Clinical Cardiology Council; Nutrition, Physical Activity, and Metabolism Council; and the Quality of Care and Outcomes Research Interdisciplinary Working Group: The American Academy of Neurology affirms the value of this guideline. Stroke. 2006;37(6):1583-1633.
4. Greenland P, Alpert JS, Beller GA, et al. 2010 ACCF/AHA Guideline for Assessment of Cardiovascular Risk in Asymptomatic Adults: Executive summary. A report of the American College of Cardiology Foundation/ American Heart Association Task Force on Practice Guidelines developed in collaboration with the American Society of Echocardiography, American Society of Nuclear Cardiology, Society of Atherosclerosis Imaging and Prevention, Society for Cardiovascular Angiography and Interventions, Society of Cardiovascular Computed Tomography, and Society for Cardiovascular Magnetic Resonance. J Am Coll Cardiol. 2010;56(25):2182-2199.

5. Expert Panel on Detection, Evaluation, and Treatment of High Blood Cholesterol in Adults. Executive summary of the Third Report of the National Cholesterol Education Program (NCEP) expert panel on detection, evaluation, and treatment of high blood cholesterol in adults (Adult Treatment Panel III). JAMA. 2001;285(19):2486-2497.

6. Klose G, Schwabe U. Lipidsenkende Mittel. [Lipid lowering drugs]. In: Schwabe U, Paffrath D, editors. Arzneiverordnungs-Report 2011. Berlin: Springer; 2010:683-698. German.

7. Phillips LS, Branch WT, Cook CB, et al. Clinical inertia. Ann Intern Med. 2001;135(9):825-834.

8. Cabana MD, Rand CS, Powe NR, et al. Why don't physicians follow clinical practice guidelines? A framework for improvement. JAMA. 1999;282(15):1458-1465.

9. Bestehorn K, Schäfer J, Gitt A, et al. Leitliniengerechte Lipidtherapie und Zielwerterreichung bei Risikopatienten im klinischen Alltag. Rationale, Ziele und Design des LIMA-registers [LIMA-register: rationale, aims and design]. MMW Fortschr Med. 2008;150(Suppl 3): S135-S141. German.

10. Sonntag F, Schaefer JR, Gitt AK, et al. Lipidtherapie im Alltag (LIMA): Leitliniengerechtes Lipidmanagement bei Patienten mit hohem kardiovaskulären Risiko in der klinischen Praxis (LIMA Register) [Lipid therapy in daily routine. Guidelines compatible lipid management of patients with high cardiovascular risk in clinical practice (LIMA registry)]. Dtsch med Wochenschr. 2012;137(40):2047-2052. German.

11. Good Epidemiological Practice (GEP): Proper conduct in epidemiologic research. Updated 2007. International Epidemiological Association; 2007 [updated April 24, 2010]. Available from: http://ieaweb.org/2010/ 04/good-epidemiological-practice-gep/. Accessed November 28, 2012.

12. Norgren L, Hiatt WR, Dormandy JA, et al; TASC II Working Group. Inter-Society Consensus for the Management of Peripheral Arterial Disease (TASC II). Eur J Vasc Endovasc Surg. 2007;33 Suppl 1: S1-S75.

13. Gitt AK, Jünger C, Smolka W, Bestehorn K. Prevalence and overlap of different lipid abnormalities in statin-treated patients at high cardiovascular risk in clinical practice in Germany. Clin Res Cardiol. 2010; 99(11):723-733.

14. Yusuf S, Hawken S, Ounpuu S, et al; INTERHEART Study Investigators. Effect of potentially modifiable risk factors associated with myocardial infarction in 52 countries (the INTERHEART study): case-control study. Lancet. 2004;364(9438):937-952.

15. Baigent C, Keech A, Kearney PM, et al; Cholesterol Treatment Trialists' (CTT) Collaborators. Efficacy and safety of cholesterol-lowering treatment: prospective meta-analysis of data from 90,056 participants in 14 randomised trials of statins. Lancet. 2005;366(9493):1267-1278.

16. Law MR, Wald NJ, Rudnicka AR. Quantifying effect of statins on low density lipoprotein cholesterol, ischaemic heart disease, and stroke: systematic review and meta-analysis. BMJ. 2003;326(7404):1423-1427.

17. Lee JMS, Choudhury RP. Prospects for atherosclerosis regression through increase in high-density lipoprotein and other emerging therapeutic targets. Heart. 2007;93(5):559-564.

18. Gitt AK, Juenger C, Jannowitz C, Karmann B, Senges J, Bestehorn K. Guideline-oriented ambulatory lipid-lowering therapy of patients at high risk for cardiovascular events by cardiologists in clinical practice: the 2L cardio registry. Eur J Cardiovasc Prev Rehabil. 2009;16(4): 438-444. 
19. Sager HB, Linsel-Nitschke P, Mayer B, et al. Physicians' perception of guideline-recommended low-density lipoprotein target values: characteristics of misclassified patients. Eur Heart J. 2010;31(10):1266-1273.

20. Hayward RA, Krumholz HM. Three reasons to abandon low-density lipoprotein targets: an open letter to the Adult Treatment Panel IV of the National Institute of Health. Circ Cardiovasc Qual Outcomes. 2012;5(1):2-5.

21. Buyken AE, von Eckardstein A, Schulte H, Cullen P, Assmann G. Type 2 diabetes mellitus and risk of coronary heart disease: results of the 10-year follow-up of the PROCAM study. Eur J Cardiovasc Prev Rehabil. 2007;14(2):230-236

22. Saely $\mathrm{CH}$, Aczel S, Koch L, et al. Diabetes as a coronary artery disease risk equivalent: before a change of paradigm? Eur J Cardiovasc Prev Rehabil. 2010;17(1):94-99.

23. Bulugahapitiya U, Siyambalapitiya S, Sithole J, Idris I. Is diabetes a coronary risk equivalent? Systematic review and meta-analysis. Diabet Med. 2009;26(2):142-148.

24. Schramm TK, Gislason GH, Køber L, et al. Diabetes patients requiring glucose-lowering therapy and nondiabetics with a prior myocardial infarction carry the same cardiovascular risk: a population study of 3.3 million people. Circulation. 2008;117(15):1945-1954.

25. Study of the Effectiveness of Additional Reductions in Cholesterol and Homocysteine (SEARCH) Collaborative Group; Armitage J, Bowman L, Wallendszus K, et al. Intensive lowering of LDL cholesterol with $80 \mathrm{mg}$ versus $20 \mathrm{mg}$ simvastatin daily in 12,064 survivors of myocardial infarction: a double-blind randomised trial. Lancet. 2010;376(9753):1658-1669.

26. FDA: Limit use of $80 \mathrm{mg}$ simvastatin. US Food and Drug Administration;2011 [updated June 8, 2011]. Available from: http:// www.fda.gov/ForConsumers/ConsumerUpdates/ucm257884.htm. Accessed November 28, 2012.

27. Knopp RH. Drug treatment of lipid disorders. $N$ Engl J Med. 1999; 341(7):498-511

28. FDA drug safety communication: New restrictions, contraindications, and dose limitations for Zocor (simvastatin) to reduce the risk of muscle injury. US Food and Drug Administration; 2011 [updated June 8, 2011]. Available from: http:/www.fda.gov/Drugs/DrugSafety/ucm256581. htm. Accessed November 28, 2012.
29. Mikhailidis DP, Lawson RW, McCormick AL, et al. Comparative efficacy of the addition of ezetimibe to statin vs statin titration in patients with hypercholesterolaemia: systematic review and meta-analysis. Curr Med Res Opin. 2011;27(6):1191-1210.

30. Zeymer U, Dechend R, Deeg E, et al; 3A Registry Investigators. Aliskiren for the treatment of essential hypertension under real-life practice conditions: design and baseline data of the prospective $3 \mathrm{~A}$ registry. Int J Clin Pract. 2012;66(3):251-261.

31. Zeymer U, Senges J, Parhofer KG, Röther J. Risk factors and event rates in patients with atherothrombotic disease in Germany: Results of the REACH registry. Dtsch Arztebl Int. 2008;105(45):769-775.

32. Ijioma N, Robinson JG. Lipid-lowering effects of ezetimibe and simvastatin in combination. Expert Rev Cardiovasc Ther. 2011;9(2): 131-145.

33. Chapman RH, Benner JS, Petrilla AA, et al. Predictors of adherence with antihypertensive and lipid-lowering therapy. Arch Intern Med. 2005;165(10):1147-1152.

34. Pittrow D, Stalla GK, Zeiher AM, et al. Prävalenz, medikamentöse Behandlung und Einstellung des Diabetes mellitus in der Hausarztpraxis. [Prevalence, drug treatment and metabolic control of diabetes mellitus in primary care]. Med Klin (Munich). 2006;101(8):635-644. German.

35. Bestehorn K, Jannowitz C, Karmann B, Pittrow D, Kirch W. Characteristics, management and attainment of lipid target levels in diabetic and cardiac patients enrolled in Disease Management Program versus those in routine care: LUTZ registry. BMC Public Health. 2009; 9:280.

36. Psaty BM, Koepsell TD, Lin D, et al. Assessment and control for confounding by indication in observational studies. J Am Geriatr Soc. 1999;47(6):749-754.
Vascular Health and Risk Management

\section{Publish your work in this journal}

Vascular Health and Risk Management is an international, peerreviewed journal of therapeutics and risk management, focusing on concise rapid reporting of clinical studies on the processes involved in the maintenance of vascular health; the monitoring, prevention and treatment of vascular disease and its sequelae; and the involvement of

\section{Dovepress}

metabolic disorders, particularly diabetes. This journal is indexed on PubMed Central and MedLine. The manuscript management system is completely online and includes a very quick and fair peer-review system, which is all easy to use. Visit http://www.dovepress.com/ testimonials.php to read real quotes from published authors. 